\title{
Introduction: Pandemics, Publics, and Politics-Staging Responses to Public Health Crises
}

\section{Kristian Bjørkdabl and Benedicte Carlsen}

\begin{abstract}
Pandemics are potentially very destructive phenomena, and for that reason, they both fascinate and frighten us. But because they might also turn out to be relatively mild, pandemics often become sites of contestation and conflict. Perhaps the most important characteristic of these diseases, then, is the fact that they are shot through with uncertainty. While they are only potentially destructive, they necessarily involve a great degree of uncertainty-and this is what makes the task of staging a collective response to pandemics such a challenge. In this introduction, we argue that a broader set of disciplines need to be engaged in the study of pandemics and other public health crises in order to prepare society for future pandemic events.
\end{abstract}

K. Bjørkdahl $(\bowtie) \cdot$ B. Carlsen

Uni Research Rokkan Centre, Bergen, Norway

e-mail: kristian.bjorkdahl@sum.uio.no

B. Carlsen

e-mail: benedicte.carlsen@uib.no

(C) The Author(s) 2019

K. Bjørkdahl and B. Carlsen (eds.), Pandemics, Publics, and Politics, https://doi.org/10.1007/978-981-13-2802-2_1 
Keywords COVID-19 - Pandemics • Uncertainty $\cdot$ Public health

We know for certain that pandemics are potentially very destructive phenomena. The most lethal ones have with good reason become the stuff of history books. To take but one particularly ravaging example, the Spanish Flu (1918-1920) claimed somewhere between 20 and 50 million lives worldwide, and infected about a third of the planet's population-etching a sombre imprint onto our collective memory (Blakely 2006). Today, 100 years later, as we keep finding new ways to bring nature under our control, many are still concerned-and some are literally terrified-that nature might "strike back" in the form of a devastating pandemic.

Creators of fiction capitalize keenly on this fear. In recent years there has been a veritable outbreak of books and films that revolve around epidemics and pandemics - set off, perhaps, by the occurrence of an actual pandemic (the so-called "swine flu") in 2009. Book readers and movie goers have been simultaneously entertained and terrified by stories such as Steven Soderberg's film, Contagion (2011), Emily St. John Mandel's sci-fi novel Station Eleven (2014), the zombie-pandemic apocalypse, World War Z (2006/2013), not to mention Margaret Atwood's hugely popular MaddAddam trilogy (2003-2013).

Such "epidemic entertainments" (see Tomes 2002) are not, however, the only discourses that make room for our pandemic fears. In The End of Epidemics, medical doctor and epidemiologist, Jonathan D. Quick, provides a telling example that pandemic alarmism even thrives within medical discourse. A future pandemic "has the potential to wipe out millions of us, including my family and yours, over a matter of weeks or months," Quick writes, adding that this "looming threat to humanity" is a scenario that "makes the threat posed by ISIS [...], a ground war, a massive climate event, or even the dropping of a nuclear bomb on a major city pale by comparison" (2018: 15):

[A] replay of the 1918 Spanish flu - against which we are not yet prepared - could hit every major city in the world within 200 days, claim more than 300 million lives, ravage national economies with the force of the Great Recession, and close public services and business around the globe. (Quick $2017)^{1}$ 
To be clear, Quick is neither an entertainer nor a creator of fiction. He is a specialist giving expert advice, and his aim is to tell us how we can improve public health preparedness around the world, so that lives that would now be lost can be saved in a future pandemic. Still, his scenarios suggest that even medical experts occasionally peddle in pandemic apocalypse.

This type of pandemic alarmism can be problematic, however. For while it is certain that pandemics can be very destructive, it is not certain that they will be so, and to stir our fears in the face of a perceived pandemic threat can all too easily turn into a situation resembling the "boy who cried wolf" (Nerlich and Koteyko 2012). To illustrate: While the seasonal influenza typically causes 290,000-650,000 respiratory deaths worldwide (WHO 2018), the death toll of the 2009 pandemictechnically termed $\mathrm{A}(\mathrm{H} 1 \mathrm{Nl})$ pdm09-has been estimated from 123,000 to 203,000 (Simonsen et al. 2013), making it an infinitely less destructive event than what the likes of Quick envision. In fact, many felt that the 2009 pandemic was one such that did not live up to its name. One commentator jokingly referred to as the "the little harmless Piglet virus" (Hafstad 2009).

At least in part because it turned out to become a so much milder disease than what was suggested by both authorities and media at the outbreak, the 2009 pandemic quickly became the scene of contestation-and it is far from the only such episode to have become just that. Why did the health authorities sound the alarm so violently? Were there really grounds for doing so? Who did sound the alarm? Was the media rather more to blame than the authorities? Did anyone have ulterior motives? What was - and what should be - the nature of the relation between the WHO, national health authorities, and the big pharmaceutical companies? Also: Might the vaccines actually be dangerous? Had the authorities in fact joined in a conspiracy with Big Pharma to drug the population?

The fact that all these questions and many more were asked during and after the 2009 pandemic, might illustrate that such episodes are shot through with uncertainty. Uncertainty, we should note, is not the same as a threat, nor is it equal to fear, though it is intimately connected with both. We can think of uncertainty as a mental and emotional space that we cannot fill using reliable methods. Our natural tendency is to fill such space, however, and in the absence of reliable methods that generates "knowledge," we proceed 
to fill it with all sorts of other things-hopes and fears, expectations and entitlements, scepticism and doubt.

One aspect of pandemic uncertainty concerns the disease itself. It is not necessarily clear, at any point in the course of a pandemic, how the disease will develop, what its effects will be. During the 2009 pandemic, for instance, scientific experts and other commentators worried that this mild disease might mutate, and hence present us with a much more acute predicament. It is part of the purpose of this book, however, to show that uncertainty in the face of a pandemic concerns much more than the epidemiology of the disease. While questions about how far and how fast the disease spreads, how lethal it will turn out to be, whether and how it will mutate, and so on, are real and important questions on which any serious pandemic response must rest, it would be wrong to think that these are the only questions that need answering, the only spaces of uncertainty that need filling. Rather, medical uncertainty is entangled with all sorts of other concerns that have little to do with the disease as such. It is the contention of this book that our pandemic perception and response is a messy blend of epidemiology and culture, medicine and politics, science and society.

More specifically, with the title of this volume, Pandemics, Publics, and Politics, we want to suggest that the epidemiology of the disease (Pandemic) will always be entangled with issues of public communication (Public), as well as with systems and practices of governance (Politics). To say that these entities are "entangled" is to point out that epidemiology and medical response are themselves communicative and political phenomena. Epidemiological research and monitoring do not take place in a cultural or social vacuum, but rather within particular institutions, where culturally conditioned actors perform more or less routinized practices according to the conventions of their historically contingent scientific disciplines. As far as output goes, the knowledge generated by this scientific community is literally of no use if it does not integrate with the systems of governance in place, or if it does not translate that knowledge into an idiom that lay people can understand and use.

For these reasons, we believe that preparedness in the face of pandemics requires a more sophisticated understanding of the many extra-medical facets of the disease. Among other things, we need to understand better how we tend to fill spaces of uncertainty with content that does not emanate from a scientific discourse, and which might 
not be what is needed in order to prepare. We need thus a broader and more heterogeneous understanding of what a "pandemic" is made up of, where that term does not simply denote a medical phenomenon which threatens human culture and society, but rather a phenomenon which, in many unpredictable ways, already is human culture and society. This does certainly not mean that we should disregard the role-actual or idealof epidemiologists. But it does mean that we should acknowledge that our capacity for pandemic response rests not on epidemiological expert knowledge alone, but also on other sorts of expertise-concerning the political systems that are designed to transform that knowledge into action, as well as concerning pandemic communication. Preparedness in the face of pandemics might even require expertise concerning "alternative expertise" or even anti-expertise movements, for how can we effectively transform medical knowledge into workable public health advice if a substantial part of the population distrusts mainstream medical knowledge?

To illustrate: Today, a case can probably be made against alarmists like Quick. A new Spanish Flu seems unlikely today, not least because medicine, and the public health apparatus, including disease prevention and control, has progressed greatly in the last 100 years. Vaccines and vaccination schemes are one obvious advance. But because pandemics are more than medical phenomena, it is uncertain how great our advances have really been. To be certain that we are now in a better position to respond to a pandemic, we would have to have made advances in our knowledge of communication and politics that could match those we have made within epidemiology.

To put it plainly, we need not just to know the new virus that emerges, but also what new forms of communication and social interaction that have emerged since the last comparable crisis. We might illustrate this by the simple fact that, since the latest pandemic, the use of social media has gone up, while the reading of traditional newspapers (and viewing of TV news) has gone down. What does it mean for a pandemic response that news is now in 2.0 mode? A whole host of sub-questions emerge: How does the so-called "\#republic" (Sunstein 2017) create new conditions in which to communicate science advice in a situation of pandemic (or similar) crisis? Where has the recent spike in vaccine skepticism come from, and how can it be countered? How does one establish credibility as epidemiological expert in a situation where an increasing number of people entertain the idea that pandemics are a conspiracy concocted by the health authorities? 
These are just some of the questions that stand out as essential, both in their own right and for the practical purpose of pandemic preparedness and response. The chapters of this book can only begin to answer some of them, and there will be much left to do. The point, however, is that if we open up the study of pandemics and pandemic response to new fields of-humanities and social science-research, we need to do so constantly, in an effort to understand how the society that constantly emerges brings with it a new set of conditions for our responsive capacity. To put it differently, a pandemic becomes a pandemic only because the disease is new, but culture and politics moves at least as fast as nature, so that, by the time a new disease looms, we do not just have a new disease to deal with, we also have to deal with the new society that has emerged since the previous pandemic. And while medical science has ways of monitoring, identifying, and responding to new viruses, we have no corresponding method for public communication or for politics. In these fields, we cannot predict the future and we are typically not in "control." This makes the ambition to learn from pandemics exceedingly difficult. To expect, argue Craddock and Giles-Vernick, that we by studying past pandemics can arrive at "a list of easy steps to follow for current and future preparedness plans or intervention measures," would be "detrimental in its simplicity and overgeneralization" (2010:2). This is not just, as they acknowledge, because "both history and pandemics are complex" (2010: 2), but because we never know where societal change will take us, and hence, what type of Publics and Politics we need to prepare for.

There is already a great deal of research done on pandemic response, and our body of knowledge is constantly being supplemented. The ownership to this object of study, however, is somewhat skewed. The great majority of research being done on pandemics is done by medical researchers or public health scholars. To some extent, this is obviously how things have to be. Pandemics are medical phenomena. But if we are right to suggest that they are also communicative and political phenomena, the issue of pandemics and pandemic response should attract the attention of a much broader range of scholarship.

Not only can pandemics and other public health crises be an interesting object of study for humanists and social scientists, but these researchers' areas of expertise are at the heart of our ability to understand and respond to such episodes. To see pandemics as entangled clusters of 
diseases, publics, and politics, is to take an interest in the particularities of how we live now. Pandemics and pandemic response alike are the products of practices of particular times and places, and we face an imperative to tackle the distinctive features that create and condition such episodes at each time and place. Today, these include such factors as the fragmentation of media, tribalization of "knowledge regimes," the increasingly troubled status of scientific and political authority, growing cross-continental mobility, as well as the globalization, commercialization, and securitization of pandemic response systems. The central questions of this book are thus: What difference do the distinctive complexities of our day make for our ability to enact appropriate pandemic response? And how can those complexities best be studied and handled?

In Chapter 2, "Global Health Governance and Pandemics: Uncertainty and Institutional Decision-Making," sociologist Sudeepa Abeysinghe shows how pandemic events require the complex architecture of global health governance to demonstrate cohesion and efficacy. She provides an example of how the WHO sought to meet this challenge during the 2009 influenza pandemic, examining the organization's role in informing and coordinating diverse global health actors, and the tensions inherent in acting swiftly and effectively in managing a pandemic. For the $\mathrm{WHO}$, Abeysinghe argues, this involved both making decisions in the face of emerging and incomplete evidence and balancing the demands of competing actors. The reward for this balancing act was not always grateful: Among other reactions, the WHO met accusations that the organization had "manufactured" the pandemic, by exaggerating the risk posed by the event.

In Chapter 3, "Uncertainty and Immunity in Public Communications on Pandemics," sociologist Mark Davis examines uncertainty in the expert advice on pandemics given to the general public. The chapter draws on research conducted in Australia and Scotland on public engagements with the 2009 influenza pandemic and discusses implications for communications on more recent infectious disease outbreaks, including Ebola and Zika. Davis shows how public health messages aim to achieve a workable balance of warning and reassurance and deflect problems of trust in experts and science. He further considers how uncertainties which prevail in pandemics reinforce the personalization of responses to pandemic risk, in ways that undermine the cooperation and collective action which are also needed to respond effectively to pandemics. 
In Chapter 4, "Enacting Pandemics: How Health Authorities Use the Press-And Vice Versa," rhetorical scholar Kristian Bjørkdahl and social anthropologist Benedicte Carlsen point out that pandemics and other public health crises typically become big news stories, but that not much is known about the dynamics that make them so. In an interview-based study of health authorities and newspaper editors in Norway, Bjørkdahl and Carlsen explore how the dynamics between these two sets of actors contributed to the mediation of the 2009 pandemic. They find that these actors made assumptions about the other party that did not match that party's understanding of itself. The authorities, in particular, relied on a communications strategy that made unrealistic-even wrongassumptions about how the media work, and this caused a need to backtrack, and adjust their communication, and also, very likely, uncertainty and even confusion in the public as to the seriousness of the disease.

In Chapter 5, “Disease Knows No Borders': Pandemics and the Politics of Global Health Security," international relations scholars Antoine de Bengy Puyvallée and Sonja Kittelsen, argue that the threat of a pandemic has gained prominence on policymakers' agendas due to the emergence and resurgence of infectious diseases and an increasingly interconnected world. Encapsulated by the phrase "disease knows no borders," this new risk environment has led to the rise of a new global health security regime, codified in the 2005 International Health Regulations and based on a paradigm of rapid detection and response to outbreak events, and a norm of collective action. Drawing on examples from the 2014-2015 Ebola epidemic, Puyvallée and Kittelsen argue that pandemic preparedness is not just a technical matter, but also a political and normative one. The authors show that the global health security regime carries tensions that reflect asymmetries in actors' capacities to put forward their priorities.

In Chapter 6, "When Authority Goes Viral: Digital Communication and Health Expertise on pandemi.no," rhetorical scholar Kristian Bjørkdahl and STS scholar Tone Druglitrø point out that our understanding and use of digital media is undoubtedly going to be a central aspect of pandemic preparedness in the future. It is still too soon to say exactly how the authorities will take advantage of the "affordances" of digital media, but one sensible assumption is that these media will create new conditions for how the authorities can establish their authority vis-à-vis the public. Bjørkdahl and Druglitrø use the Norwegian government's 2009 pandemic website, pandemi.no, as a case, and study its ways 
of establishing authority through its use of the website's various material possibilities. Arguing that the site somewhat paradoxically rests in a strikingly traditional conception of health expertise, Bjørkdahl and Druglitrø reflect on how the materiality of digital media can and should be used to communicate about pandemics in the future.

\section{Note}

1. Jonathan D. Quick, "Why I Wrote The End of Epidemics," 28 November 2017. https://www.msh.org/blog/2017/11/28/why-i-wrote-the-endof-epidemics.

\section{REFERENCES}

Blakely, Debra. 2006. Mass Mediated Disease: A Case Study Analysis of Three Flu Pandemics and Public Health Policy. Lanham: Lexington Books.

Giles-Vernick, Tamara, Susan Craddock, with Jennifer Gunn. 2010. Influenza and Public Health: Learning from Past Pandemics. London: Earthscan.

Hafstad, Anne. 2009. Hva skal vi tro? Aftenposten, 31 October, p. 3.

Nerlich, Brigitte, and Nelya Koteyko. 2012. Crying Wolf? Biosecurity and Metacommunication in the Context of the 2009 Swine Flu Pandemic. Health o Place 18 (4): 710-717.

Quick, Jonathan D. 2017. Why I Wrote The End of Epidemics, 28 November. https://www.msh.org/blog/2017/11/28/why-i-wrote-the-end-of-epidemics.

Quick, Jonathan D. 2018. The End of Epidemics: The Looming Threat to Humanity and How to Stop It. New York: St. Martin's Press.

Simonsen, Lone, Peter Spreeuwenberg, Roger Lustig, Robert J. Taylor, Douglas M. Fleming, Madelon Kroneman, Maria D. Van Kerkhove, Anthony W. Mounts, W. John Paget, The GLaMOR Collaborating Teams. 2013. Global Mortality Estimates for the 2009 Influenza Pandemic from the GLaMOR Project: A Modeling Study. PLoS Medicine 10 (11): el001558. https://doi. org/10.1371/journal.pmed.1001558.

Sunstein, Cass. 2017. \#Republic: Divided Democracy in the Age of Social Media. Princeton: Princeton University Press.

Tomes, Nancy. 2002. Epidemic Entertainments: Disease and Popular Culture Early-Twentieth-Century America. American Literary History 14 (4): $625-652$.

WHO. 2018. Influenza (Seasonal). WHO Fact Sheet. http://www.who.int/ mediacentre/factsheets/fs211/en/. 